\title{
A socialização como fato social total: notas introdutórias sobre a teoria do habitus*
}

\author{
Maria da Graça Jacintho Setton \\ Universidade de São Paulo, Faculdade de Educação
}

\section{Introdução}

Em "Ensaio sobre a dádiva. Forma e razão da troca nas sociedades arcaicas" (1974), Marcel Mauss, analisando o regime de direito contratual e o sistema de prestações econômicas de sociedades ainda chamadas primitivas, apresenta a noção de fato social total. Mauss (1974, p. 41) refere-se a um conjunto enorme de fatos que se relacionam de maneira complexa. Nesses fenômenos,

\section{[...] tudo se mistura, tudo o que constitui a vida propriamente social das sociedades que precederam as nossas - até as da proto-história. Nesses fenômenos sociais “totais”, como nos propomos chamá-los, exprimem-se, ao mesmo tempo e de uma só vez, toda espécie de instituições: religiosas, jurídi-}

* Estas reflexões estão sendo desenvolvidas a partir da pesquisa Família, escola e mídia: um estudo sobre as práticas de socialização contemporâneas, financiada pela Fapesp, nos anos de 2005/2007. O estudo teve como objetivo investigar a importância das matrizes de cultura - família, religião, escola e mídias - na construção dos habitus de jovens do ensino médio, no Norte e no Sudeste do Brasil. cas e morais - estas políticas e familiais ao mesmo tempo; econômicas - supondo formas particulares de produção e de consumo, ou antes, de prestação e de distribuição, sem contar os fenômenos estéticos nos quais desembocam tais fatos e os fenômenos morfológicos que manifestam estas instituições.

Ao longo desse texto, Mauss relata as principais características dos fenômenos sociais totais partindo do exemplo das trocas de bens e do contrato de contraprestação de presentes realizado em algumas sociedades da Oceania e da América do Norte. Para os interesses dessa reflexão, seria interessante apreender algumas dessas ideias, pois elas ajudam a desenvolver o argumento de que a socialização ${ }^{1}$ pode ser igualmente vista como um fenômeno social total. ${ }^{2}$ Procurar uma analogia entre o fenômeno das

\footnotetext{
${ }^{1}$ Segundo Guy Vincent (2004), a socialização deve ser
} pensada como um processo incessante de se fazer, de se desfazer e se refazer a partir das relações sociais; uma certa maneira de ser e estar no mundo, sendo necessário, portanto, pensá-la a partir do verbo reflexivo socializar-se.

${ }^{2}$ Ainda que alerte para o fato de que os fenômenos totais são 
trocas dessas sociedades e a socialização enquanto fato social amplo e complexo, ou seja, analisar as práticas socializadoras nas suas dimensões econômica, moral, estética e política, é uma forma de melhor compreendê-la e contextualizá-la no mundo contemporâneo.

Vale salientar que não se trata de um exercício de erudição acadêmica, mas uma construção reflexiva que ajuda a circunscrever as instâncias de socialização numa perspectiva relacional, tendo como eixo central a participação do sujeito social em seu processo educativo. Mais do que isso: ajuda a pensar essas instâncias em suas dimensões econômica, moral, estética e política, responsáveis pela formação de um habitus, sistema de disposições, tal como pensando por Pierre Bourdieu. Considera-se que o processo de socialização das formações atuais é um espaço plural de múltiplas referências identitárias. Ou seja, a contemporaneidade caracteriza-se por oferecer um ambiente social em que o indivíduo encontra condições de forjar um sistema de referências que mescle as influências familiar, escolar e midiática (entre outras), um sistema de esquemas coerente, no entanto híbrido e fragmentado. Embora se saiba que, no contexto atual, cada uma das instâncias formadoras desenvolve campos específicos de atuação, lógicas e valores éticos e morais distintos, considera-se ainda que são os próprios indivíduos quem tecem as redes de sentido que os unificam em suas experiências de socialização. É o indivíduo que tem a capacidade de articular as múltiplas referências que lhe são propostas ao longo de sua trajetória. É o sujeito a unidade social na qual se podem efetivar diferentes sentidos de ações, ações essas derivadas de suas múltiplas esferas de existência. No sujeito cruzam-se e interagem sentidos particulares e diferentes. Ele não é apenas o

manifestações frequentes em sociedades que ainda não desenvolveram contratos individuais puros, onde os mercados não fazem circular dinheiro, vendas ou mesmo a noção de preço, crê-se que ele inspira compreender, em formações complexas e globalizadas como as nossas, aspectos da educação que são fortes e predispõem toda a sociedade a se dedicar, voluntária e inconscientemente, a ela, mas, ao mesmo tempo, numa espécie de contrato obrigatório. único portador efetivo de sentidos, mas a única sede possível de relações entre eles. ${ }^{3}$

Assim sendo, está-se optando por uma perspectiva sociológica. Ou seja, busca-se a relação dialética entre indivíduo e sociedade. Busca-se uma forma de interpretar as ações sociais, as práticas coletivas com base em uma troca incessante entre as duas faces de uma mesma realidade (o indivíduo e as matrizes sociais de cultura). Analisando o processo de socialização a partir da articulação das ações educativas de várias instâncias produtoras de bens simbólicos, busca-se compreender o jogo da reciprocidade e interação estabelecido pelos sujeitos. Em outras palavras, pretende-se apreender a dinâmica do campo da socialização contemporâneo a partir da tensão entre agentes socializadores, e, como consequência, a apreensão de uma luta simbólica de valores entre eles. Parte-se metodologicamente da experiência de indivíduos social, temporal e culturalmente diferenciados. ${ }^{4}$

Trabalha-se com a hipótese da existência de vários modelos de articulação entre as matrizes de sentido responsáveis pela formação de sujeitos sociais singulares. Assim sendo, cabe perguntar: qual o papel de cada uma dessas instâncias na vida dos sujeitos

${ }^{3}$ As noções de indivíduo, sujeito e agente social são aqui usadas como sinônimos. Saliento, todavia, que parto do pressuposto de que o sujeito social tem participação ativa no processo de socialização. Numa contínua troca simbólica, a relação entre ele e as instituições que o rodeiam é que mantém e transforma as estruturas do mundo coletivo.

${ }^{4}$ A socialização aqui é compreendida como um processo que busca a construção de um ser social. Seu caráter é contratual, revestido de forte conteúdo moral e ético, pois implica a orientação segundo padrões de comportamento definidos e legitimados $a$ priori. Entretanto, esse processo pode ser pensado sob dois pontos de vista: ora como imposição de padrões à conduta individual, sendo muitas vezes definido como processo de condicionamento e controle da sociedade sobre os indivíduos; ora como processo de aquisição de conhecimento e aprendizado, interiorização de padrões de conduta que os tornam mais humanos e civilizados. Dessa reflexão apreende-se a ambiguidade do processo e o caráter ideológico da formação das identidades sociais. 
sociais? Quais os pontos de ruptura ou convergência entre elas? De outra forma, como se estabelece a composição do habitus dos indivíduos contemporâneos? Como pensar a ação, ou seja, a força e a determinação das múltiplas agências socializadoras e suas distintas referências na construção do indivíduo da atualidade?

Ao considerar a socialização contemporânea como um fato social total, a intenção não é se apropriar da noção das trocas contratuais, potlach ou kula, de forma mecânica e linear. Ao contrário, o interesse é se apropriar dessa noção como um instrumento de análise que ajude a pensar a educação como um fenômeno geral e generalizado, que implica necessariamente uma troca, uma reciprocidade - ainda que tensa, e, às vezes, em forma de luta -, sob pena de colocar a vida social em risco. Um fenômeno que envolve a todos e que, para se realizar, manifesta-se nas dimensões econômica (origem social), política (posição ideológica), religiosa (crença) e estética (gosto) na vida de todos. Como lembra Mauss, depois de um tanto forçadamente haver dividido e abstraído sobre algumas das matrizes de cultura, é preciso que os sociólogos se empenhem em recompor o todo.

Mas o fato total não chega a ser total pela simples reintegração dos aspectos descontínuos: familiar, escolar, religioso, midiático de cada um deles; é preciso ainda que o fato social total se encarne em uma experiência individual. Ou seja, primeiro em uma história individual que permita observar o comportamento dos seres totais e não divididos em faculdades; segundo, a partir de um sistema de interpretação que simultaneamente considere os múltiplos aspectos (físico, psíquico, sociológico) de todas as condutas.

\footnotetext{
O fato social total apresenta-se, pois, com um caráter tridimensional. Deve fazer coincidir a dimensão propriamente sociológica com seus múltiplos aspectos sincrônicos; a dimensão histórica, ou diacrônica; e, finalmente, a dimensão fisio-psicológica. Ora, é só nos indivíduos que esta tríplice abordagem pode ser feita. [...] A noção de fato social total está em relação direta com a dupla preocupação, que para nós havia parecido única até agora, de ligar o social e o individual de um lado, o físico (ou o fisiológico) e o psíquico de outro. (Levi-Strauss, 1974, p. 14-15)
}

Para desenvolver esse argumento, passa-se a fazer uso agora de duas maneiras de interpretar as práticas e as ações sociais do mundo contemporâneo. Mais especificamente, dar-se-á ênfase a duas teorias da ação que discutem o processo de socialização. Esta reflexão ater-se-á a dois autores que marcaram decisivamente esse campo de investigação. A primeira refere-se a Pierre Bourdieu e sua teoria do habitus. A segunda, a Bernard Lahire, que em uma interpretação particular e crítica a Bourdieu propõe uma leitura contemporânea da socialização, cunhando a expressão homem plural.

\section{O homem plural frente à teoria do habitus de Pierre Bourdieu}

Bernard Lahire é atualmente professor da École Normale Superieure Lettres et Sciences Humaines e diretor do grupo de pesquisa sobre socialização no Centre National de la Recherche Scientifique (CNRS), na Universidade Lumière, Lyon 2, França. ${ }^{5}$ Tem como tema central de suas pesquisas o processo de socialização, a sociologia das disposições sociais e culturais, eixos temáticos que proporcionam abertura para discutir a sociologia da educação e a sociologia da cultura.

Lahire é também grande admirador e, ao mesmo tempo, grande crítico da obra de Bourdieu. É possível observar em seus escritos uma acentuada necessidade de problematizar uma das principais contribuições deste autor. Como ele mesmo diz, trabalha a favor e contra Bourdieu o tempo todo (Lahire, 2002, p. 11). Um dos pontos centrais da tese de Lahire é questionar a teoria da prática de Bourdieu, a teoria da ação dos agentes sociais, principalmente no que se refere à teoria do habitus.

Segundo Lahire, não se pode pensar o indivíduo contemporâneo sendo regido apenas por um único

${ }^{5}$ De carreira meteórica, tem se dedicado a um grande número de pesquisas, e sua produção intelectual é invejável. Perto dos cinquenta anos de idade, alcançou espaço de destaque na academia francesa. Hoje já é possível contabilizar um número expressivo de livros publicados e uma infinidade de capítulos e artigos em periódicos franceses e internacionais. 
princípio de conduta. Hoje, cada vez mais as crianças são socializadas com base em uma multiplicidade de princípios, o que poria em xeque a teoria do habitus. Ele considera que Bourdieu engessou a própria sociologia ao consolidar um único olhar sobre a teoria das disposições culturais, a teoria do habitus. Os indivíduos, segundo ele, não agiriam de forma homogênea nas muitas situações de vida, não agiriam coerentemente o tempo todo a partir de um sistema de disposições homogêneo, coerente e único. Apoiado no conceito de habitus, Lahire afirma que Bourdieu constrói um homem perfeito, enquanto a realidade demonstra ser o indivíduo altamente complexo (Lahire, 2004a).

Para melhor apresentar a discussão proposta, Lahire considera que existem duas correntes de pensamento sobre a teoria da ação. Grosso modo, a primeira, baseada na unicidade do ator; a segunda, baseada na sua fragmentação interna. De um lado, pesquisa-se sobre a visão de mundo, a relação com o mundo ou a fórmula geradora das práticas; de outro, admite-se a multiplicidade de saberes incorporados, de experiências vividas, do "eu” e dos papéis interiorizados pelo ator. Segundo Lahire, o interesse principal da primeira posição é expresso por Bourdieu, pois para ele a teoria do habitus permite construir e compreender de maneira unitária as dimensões da prática que são frequentemente estudadas de modo disperso, dando ênfase ao caráter sistemático e unificador das condutas (Lahire, 2002).

Afirmar que cada dimensão do estilo de vida simboliza as outras, que cada domínio das práticas é uma relação metafórica semelhante a todas as outras parece para Lahire terrivelmente homogeneizante. A teoria do habitus é compreendida aqui como um princípio ativo de unificação das práticas e de representações. O conceito de habitus contribui, sem nada conceder ao empírico, para a segurança de uma ilusão socialmente bem fundada. Para Lahire, é um mito a identidade pessoal invariável. E mais: dirá que existe uma multiplicidade nos sistemas de hábitos incorporados ligados a diferentes domínios da existência e universos sociais que a teoria do habitus de Bourdieu não contemplaria (Lahire, 2002, 2004a, 2006).
Segundo Lahire, a questão da unicidade ou da pluralidade do ator é uma questão histórica tanto quanto teórica. A questão deve ser posta nestes termos: quais são as condições sócio-históricas que tornam possível um ator plural ou um ator caracterizado por uma profunda unicidade? Ao escrever o prefácio da obra de Panofsky, ${ }^{6}$ apropriando-se das ideias desse autor, Bourdieu não abordaria a questão da excepcionalidade do contexto histórico analisado. Se o tivesse feito, teria que relativizar a unicidade, a durabilidade e a transferência de esquemas ou de disposições constitutivas do habitus. Ainda de acordo com Lahire, os primeiros trabalhos de Bourdieu, nos anos de 1960, levaram-no a construir uma teoria do ator e da ação mais sensível à pluralidade de esquemas de experiências incorporadas. Nesses trabalhos relativos à sociedade Cabilia, Bourdieu (1963) oscilaria entre o modelo do desdobramento do social e mental, que supõe que os atores se utilizam de maneiras de pensar e de agir diferentes e muitas vezes contraditórias, em ambientes e universos sociais diferentes, aquele que implica a mistura, na confusão de gêneros e de registros, e finalmente a contradição no coração mesmo de cada prática (Lahire, 2002).

Para Lahire, o paradoxo da construção da teoria do habitus reside em ter concebido a adaptação de um sistema de disposições em sociedades pouco diferenciadas e transferido esse esquema para as sociedades modernas, altamente heterogêneas. Em espaços como a família, a escola, os amigos e/ou as múltiplas instituições culturais, que os indivíduos são levados a frequentar, pode-se observar demandas diversificadas, concorrentes e, às vezes, contraditórias no que se refere aos princípios da socialização (Lahire, 2002).

Assim, Bernard Lahire considera que a produção homogênea do habitus em todas as esferas da vida é um sonho. As disposições culturais desejadas e programadas apresentam resistências: interesses mobilizados em direção oposta, públicos diferentes, referências concorrentes etc. A coerência dos esquemas de ação,

\footnotetext{
${ }^{6}$ Texto que se encontra no livro A economia das trocas
} simbólicas, de 1982, com o título "Estrutura, habitus e prática". 
as disposições de habitus que os atores podem interiorizar dependem da coerência dos princípios de socialização a que estão submetidos. Desde que um ator esteja simultânea e sucessivamente no seio de uma pluralidade de mundos sociais não homogêneos e às vezes contraditórios, ou no seio de universos sociais relativamente coerentes mas apresentando em certos aspectos contradições, expomo-lo a um estoque de esquemas de ação ou de habitus não homogêneos, não unificados e, consequentemente, a práticas heterogêneas, variando segundo o contexto social no qual será levado a valorizar (Lahire, 2002).

Mais do que considerar a coerência e a homogeneidade dos esquemas que compõem o estoque de cada ator individual como uma situação padrão, aquela que é a mais observável em uma sociedade indiferenciada, é preferível pensar que essa situação é mais improvável, a mais excepcional. Para ele, é mais frequente observar atores individuais menos unificados e portadores de habitus heterogêneos e, em certos casos, opostos e contraditórios. Aquilo que se vive com a própria família, na escola, com os amigos ou alhures não é sinteticamente somado de maneira tão simples. Sem postular uma lógica de descontinuidade absoluta pressupondo que esses contextos são radicalmente diferentes, sugere pensar que todas as experiências não são sistematicamente coerentes, homogêneas e, mesmo, compatíveis. Além disso, cada vez mais o contato precoce com outros universos além da família está presente na vida (creches, televisão, empregadas domésticas). É difícil pensar em um universo coerente e harmonioso mesmo em relação ao universo familiar. É forçoso constatar que a experiência da pluralidade de mundos tem todas as chances de ser precoce nas sociedades atuais. Para Lahire, vive-se simultânea e sucessivamente em contextos sociais diferenciados e não equivalentes. Um olhar microssociológico permite observar, em espaços relativamente homogêneos, diferenças internas importantes nas interações e nas situações sociais em que se vive. $\mathrm{O}$ autor vai mais adiante: para ele é difícil encontrar configurações familiares absolutamente homogêneas. Poucos são os casos em que o universo familiar é coerente, produ- tor de disposições gerais orientadas em uma mesma direção. É preciso ver a heterogeneidade interna dos ambientes familiares, o cruzamento de orientações distintas no seio familiar (Lahire, 2002, 2004a).

Além disso, lembra Lahire, por não ocupar posições semelhantes em todos os espaços sociais, vivem-se experiências variadas, diferentes e, às vezes, contraditórias. Um ator plural é, então, produto de experiências - cada vez mais precoces - de socialização em contextos sociais múltiplos e heterogêneos. Pertence simultânea e sucessivamente, no curso de sua trajetória, a universos sociais variados ocupando posições diferentes. Em síntese, todo indivíduo exposto a uma pluralidade de mundos sociais se submete aos princípios de socialização heterogêneos e, às vezes, contraditórios e, em assim sendo, não responderia ou agiria segundo um sistema único de disposições de habitus.

\section{Problematizando a crítica}

Ainda que muito do que Lahire apresentou seja um avanço em relação à teoria da socialização, o que se demonstrou em outro contexto (Setton, 2005), pensase que para os interesses desta reflexão deveria-se, primeiramente, fazer algumas considerações de ordem mais geral a respeito de sua obra.

No que se refere à sua crítica à teoria do habitus de Bourdieu, sem dúvida, Lahire deve ser parabenizado por alertar para uma série de vícios que uma sociologia mal fundamentada e pouco exigente pode fazer com a teoria proposta por Bourdieu. Ou seja, dada a importância e legitimidade deste autor, é comum se observar o uso de seus conceitos, teorias e/ ou teses principais sem que haja de fato uma leitura atenta e bem circunstanciada de cada uma delas. Temse ciência de um mau aproveitamento dos conceitos cunhados por ele, tais como capital cultural, capital social e mesmo o conceito de campo. Vê-se também que muito da teoria do Bourdieu pode ser falsamente importada sem que haja contextualização de suas teses. Por exemplo, falar de capital cultural ou da influência da escola como espaço formador de habitus em um 
país como o Brasil deve ser devidamente mediado pela compreensão de uma estrutura social e um sistema escolar seguramente diferente daquele que inspirou o autor.

Acredita-se também que grande parte das críticas que Lahire tece a Bourdieu tem origem em perspectivas metodológicas distintas entre os autores. Bourdieu sempre fez uma sociologia dos grupos sociais e das formas de dominação existentes em uma sociedade hierarquizada segundo a divisão desigual de poderes e privilégios. Com forte caráter inovador, a sociologia de Bourdieu poderia ser compreendida como uma sociologia política, pois conseguiu apontar, em temas como gosto (Bourdieu, 1979), o campo da alta costura (2002) ou a frequência a museus (Bourdieu, 1969; Bourdieu \& Darbel, 2003), uma estrutura social organizada segundo diferenças econômicas e culturais. Suas análises, ainda que adensadas por um olhar antropológico, sempre partiram de um ponto de vista estatístico e macrossociológico.

A teoria do habitus, construída por Bourdieu e empiricamente verificada no estudo sobre a variação do gosto cultural entre segmentos sociais franceses, na década de 1970, foi pouco questionada na ocasião de sua publicação, pois surgiu em um ambiente intelectual altamente favorável ao questionamento da ordem escolar. Parte da academia apropriou-se dessas ideais porque vinham reforçar as denúncias das estruturas perversas de reprodução da ordem social via sistema de ensino. Ainda que Bourdieu tivesse denunciado os mecanismos de dominação cultural e as variadas formas de emprego de uma violência simbólica em distintos campos sociais, sua intenção, na ocasião, era questionar as correntes ideológicas em disputa na época, como as teorias do capital humano e uma sociologia da educação economicista ou estritamente pedagógica (Bourdieu, 1998).

Mas acredita-se que fundamentalmente a crítica que Lahire faz de Bourdieu trata da necessidade de refundar um campo reflexivo dentro da sociologia. Lahire parece querer retomar uma outra forma de fazer sociologia e, para isso, precisa apontar pontos de ruptura entre sua forma de fazer e a forma de fazer a sociologia bourdieusiana. Tudo leva a crer que Lahire quer fundamentar o alcance de uma sociologia do indivíduo. Seus últimos trabalhos, O homem plural (2002), Retratos Sociológicos (2004a) e, mais recentemente, A cultura dos indivíduos (2006), são dedicados a formular um fazer sociológico fundado no individuo. No entanto, alerta, propõe ser diferente das teorizações sobre os sujeitos, tal como os interacionistas, os fenomenólogos ou a própria Psicologia. Segundo ele, para caracterizar o social não é necessário se ater às grandes categorias como classe, sexo ou idade ou mesmo raça e religião. Uma série de outros aspectos pode ser determinante e agir de forma a influir nas práticas de cada um. Mesmo compreendendo que esses primeiros sejam aspectos fundamentais, quer direcionar um olhar para as diferenças internas entre os indivíduos que não se reduzem às grandes categorizações.

Para Lahire, o social não se reduz ao coletivo ou ao geral, mas marca sua presença nos aspectos mais singulares de cada indivíduo. Um grande número de disposições não está relacionado às condições sociais, de classe ou trajetória. Algumas, até aquelas mais recorrentes dos traços de personalidade e de temperamento, não são produto das condições de existência material; no entanto, não deixam de ser de ordem social (Lahire, 2006).

Partidário, então, de uma sociologia do indivíduo ou de suas singularidades, o autor pretende dar um salto em relação às teorias sociológicas, mais propriamente à sociologia da socialização. Segundo seu ponto de vista, a teoria sociológica passa, há um certo tempo, por um estado de letargia, aceitando sem questionamentos a teoria da prática de Bourdieu. Pretende, então, apontar os erros que a sociologia vem sistematicamente seguindo ao ocultar a possibilidade de construir um outro olhar sobre a realidade do social, bem como o que a própria ciência da sociedade acrescentaria e ganharia em esclarecimento se estivesse aberta para outra leitura (Lahire, 2004a, 2006).

Apresenta, pois, a intenção de fazer um estudo sociológico a partir da configuração disposicional dos sujeitos singulares utilizando as noções real dobrado (individualizado) e real desdobrado (dessin- 
gularizado). Nesta versão desdobrada da realidade, o individuo é definido pelo conjunto de suas relações, compromissos, pertencimentos e propriedades passados e presentes. Nele se sintetizam ou se combatem, combinam-se ou coexistem, de forma mais ou menos pacífica, elementos e dimensões de uma cultura que geralmente são estudados separadamente pelos pesquisadores das ciências sociais. Mas o mundo social não é construído dessa maneira, o indivíduo não segue essas mesmas divisões; o mesmo indivíduo pode ser escolarizado, protestante e comerciante etc. Cada indivíduo diferencia-se de todos os outros. Essa versão dobrada (individual) do social não substitui a versão desdobrada, mas no longo prazo permite torná-la mais complexa (Lahire, 2004a).

Para Lahire, ao captar as razões das variações intraindividuais dos comportamentos e a complexa articulação dos patrimônios de disposições individuais dos contextos de seu desencadeamento ou de seu estado de vigília, compreender-se-á o que muitas vezes a sociologia não explicou até agora. Ou seja, retomam-se de forma crítica os instrumentos de pensamento de uma tradição teórica em matéria de teoria da ação. Os atores não são movidos por puras e simples determinações internas e/ou disposições que, mencionam, não podem ser reduzidas a rotinas. Ele admite que Bourdieu registrou o maior esforço de explicitação em matéria de teoria disposicionalista da ação. Não obstante, lembra ele, como habitualmente está-se acostumado a esse vocabulário, supõe-se que se sabe o que é uma disposição, um esquema ou uma fórmula geradora de práticas. Esse conformismo não molda a própria maneira de ver?, indaga. Assim, propõe fazer uso controlado e reflexivo desse aporte teórico (Lahire, 2004a).

Segundo Lahire, a disposição é uma realidade reconstruída que, como tal, nunca é observada diretamente pelo cientista social. Ela pressupõe a realização de um trabalho interpretativo para dar conta de comportamentos, práticas e opiniões. Trata-se de fazer aparecer os princípios que geraram a aparente homogeneidade e/ou diversidade de práticas e gostos. Para ele, é necessário perguntar que tipo de limitação o conceito de disposição oferece ao pesquisador e que tipo de metodologia deve-se usar para acompanhar seu estudo. Mais do que um certo conformismo teórico, Lahire faz uma critica conceitual aos trabalhos que usam com pouca seriedade a contribuição de Bourdieu. Crê que as noções de disposição e transferibilidade devem ser mais bem esclarecidas, a fim de poder avançar na compreensão do social. Em seu livro Sucesso escolar nos meios populares, essa discussão está mais presente. Nessa obra, discute o conceito de capital cultural na sua forma de herança transferível de cultura. Problematiza as formas homeopáticas, osmóticas dos comportamentos culturais, dizendo ser necessário duvidar dessa força formadora. Propõe, então, observar as condições de transferência, as condições de transmissão desse capital cultural, as formas de cultura escrita, o trabalho pedagógico das famílias populares, entre outros aspectos.

Nas suas discussões mais recentes, em $O$ homem plural e A cultura dos indivíduos, Lahire parte da hipótese de que o indivíduo se socializa a partir de uma pluralidade e de uma heterogeneidade de disposições incorporadas, não agindo sobre o mundo, não construindo suas práticas seguindo um princípio único norteador. Para ele, o indivíduo faz uso de uma grande variedade de referências disposicionais, às vezes referências incoerentes ou até mesmo contraditórias. Aposta na pluralidade das fórmulas geradoras das práticas incorporadas.

Nesse sentido, ele de fato avança nas discussões sobre o tema na contemporaneidade. Para contextualizar uma nova configuração de socialização no mundo moderno, considera as mudanças sofridas nas relações familiares, fazendo, de suas colocações, leituras imprescindíveis. Chama a atenção também para a necessidade de melhor circunstanciar as diferentes formas de produzir disposições culturais.

Não obstante, acredita-se que suas críticas podem ser problematizadas. Argumentar que Bourdieu apenas formulou a ideia de herança cultural sem se preocupar em apreender como isso se dá efetivamente na realidade cotidiana é uma afirmação injusta. Bourdieu (1964a, 1964b) e sua equipe publicaram uma série de estudos sobre as estratégias de reprodução social das 
famílias de elite que delimitam e contextualizam um conjunto de situações em que as práticas de cultura, o gosto pela cultura ou a familiaridade com a cultura letrada são transmitidos ou não. Lahire parece se esquecer ainda de uma longa tradição de trabalhos da equipe de Bourdieu na École de Hautes Éstudes en Sciences Sociales, em Paris, entre eles o de Monique de Saint Martin, trabalhos que ecoaram também no Brasil (Almeida \& Nogueira, 2003).

Para o interesse deste artigo, crê-se ser importante enfatizar, no entanto, suas críticas relativas ao conceito de habitus. Para esse crítico, Bourdieu formalizou e sistematizou o entendimento do conceito de habitus em uma formação já fortemente diferenciada.

Em síntese, segundo o argumento que desenvolve em O homem plural, é que se define o habitus como um sistema homogêneo de disposições gerais, permanentes, sistemas transferíveis de uma situação a outra, de um domínio de práticas a outro, então cada vez menos agentes de nossas sociedades serão definíveis a partir de um tal conceito. [...] Nas sociedades em que as crianças conhecem muito cedo uma diversidade de contextos socializantes, os patrimônios individuais de disposições raramente são muito coerentes e homogêneos (Lahire, 2002).

Ainda que se considere sua contribuição inegável, acompanhando com interesse o desenvolvimento de seus argumentos, pensa-se que a compreensão de Lahire sobre a teoria da ação ou a teoria do habitus de Bourdieu deve ser repensada.

\section{Habitus como produto de um esforço coletivo e individual}

Diferentemente de Lahire, acredita-se que o conceito de habitus, tal como discutido por Bourdieu, pode ainda dar conta da especificidade da formação da identidade pessoal e grupal dos indivíduos na contemporaneidade. Mais do que isso; crê-se que o conceito de habitus segundo Bourdieu fundamenta a hipótese de que é preciso compreender o fenômeno da educação/ socialização, principalmente na atualidade brasileira, como total. Não totalizante, mas exatamente o contrá- rio, fruto de um processo amplo, estruturado a partir de uma multiplicidade de experiências formadoras, que resulta em um habitus híbrido. Considera-se importante registrar ainda que se parte de uma perspectiva relacional, indivíduo e sociedade, não dando ênfase a qualquer dos dois lados da moeda, tal como poderia correr o risco Lahire, em sua tentativa de construir uma sociologia do indivíduo.

O entendimento que se faz sobre a teoria do habitus poderia incluir, sim, o adjetivo plural. Considerase expressivo, ou seja, que habitus plural resulta do encontro e/ou enfrentamento de muitas referências, às vezes díspares, mas salienta-se que, não deixaria de ser um sistema único de referência, uma matriz geradora de disposições, ainda que sejam disposições heterogêneas. Em outras palavras, um habitus plural, mas ainda se apresentando na forma de um de sistema, capaz de gerar princípios de ação, percepção e julgamento. (Setton, 2002a) Mesmo que as ações dos sujeitos não sejam tão coerentes, mesmo que apresentem fissuras e aspectos contraditórios, a prática do agente contemporâneo é resultado da confluência de várias vivências, por isso capaz de ser pensado enquanto unidade, como um fato social total. Ou seja, produto de vivências de socialização contextualizadas em muitas matrizes culturais, presentes na vida de cada um de nós, experimentadas sobretudo em situações coletivas.

Circulando desde a primeira infância na família, o indivíduo estrutura-se e se prepara para vivenciar, aproveitando ou não, as chances de se subjetivar na escola, nas experiências religiosas e/ou na circularidade de influências disponibilizadas pelas mídias (ou em outros espaços). Assim, pensar o indivíduo contemporâneo a partir da configuração de forças entre essas agências de socialização impõe um outro aporte teórico, impõe a necessidade de compreender esse processo de maneira mais complexa e dinâmica. Como diria Levi-Strauss (1974, p. 15):

\footnotetext{
[...] a noção de fato total está em relação direta com a dupla preocupação, que para nós havia parecido única até agora, de ligar o social e o individual, de um lado, o físico (ou o fisiológico) e o psíquico de outro. Mas compreendemos melhor
} 
a razão disso, que é dupla: de um lado, é apenas ao término de toda uma série de reduções que se estará na posse do fato total, que compreende: 1) diferentes modalidades do social (jurídico, econômico, estético, religioso etc.; 2) diferentes momentos de uma história individual, nascimento, infância, educação, adolescência, casamento etc. 3) diferentes normas de expressão, desde fenômenos fisiológicos como reflexos, secreções, afrouxamentos e acelerações, até categorias inconscientes e representações conscientes, individuais ou coletivas. Tudo isto é, num certo sentido, social, uma vez que é apenas sob a forma de fato social que esses elementos de natureza tão diversa podem adquirir uma significação global e tornar-se uma totalidade.

Para o encadeamento dessa discussão, seria interessante lembrar que, nos textos relativos ao conceito de habitus, Bourdieu enfatiza-o como um sistema de disposição que se compõe a partir da complementação, e quase nunca a partir da incoerência entre matrizes de cultura (Bourdieu, 1979, 1983b, 1998). ${ }^{7} \mathrm{O}$ autor trabalha o conceito de habitus escolar, por exemplo, como resultado de uma sinergia entre projetos pedagógicos da família e da escola. Ou seja, a ênfase de Bourdieu sempre recai na complementação e quase nunca na incoerência das influências que moldam os habitus dos indivíduos (Bourdieu, 1964a, 1964b, 1979). Seria porque os espaços socializadores por ele trabalhados - família e escola - dependem de uma sinergia interna forte, o que de certa forma contribui para a construção do conceito de capital cultural? Seria porque sua fonte de verificação empírica não lhe propunha o desafio de pensar a incoerência? Seria porque Bourdieu não tinha como inquietação as transformações pelas quais a sociedade contemporânea estava passando? Seria ainda porque sua preocupação era observar as estruturas de dominação ainda expressivamente importantes, observadas na tradição, na herança de cultura na França dos anos de 1970, e da escola ainda como espaço

${ }^{7}$ Em alguns momentos coloca a incongruência das ações e práticas como uma alodoxia, um desvio que poderia ser explicado também sociologicamente (Bourdieu,1979). privilegiado? Crê-se que todos esses motivos sejam pertinentes e poderão trabalhar em sinergia.

Pensa-se que é possível divergir de Lahire quando ele afirma que a teoria do habitus de Bourdieu não é mais produtiva para pensar o homem contemporâneo, pois Bourdieu o construiu a partir de uma base sistêmica e unitária, homogênea. Um mundo socializador que não existe mais nas formações modernas.

Em trabalho anterior, é exposto o entendimento sobre essa questão (Setton, 2002a). Habitus, segundo essa leitura, é um conceito, e assim deve ser circunstanciado historicamente, conceito que expressa a mediação indivíduo-sociedade; é princípio explicativo das práticas e das representações de indivíduos em conjunturas específicas e particulares. Habitus deve ser visto como mediação que se constrói processualmente, em muitos momentos da trajetória dos sujeitos, conjunto de experiências acumuladas e interiorizadas, incorporadas; portanto, passíveis de se sedimentar e se realizar como resposta aos momentos de necessidade. Sendo espontâneos em momentos de tranquilidade identitária ou repensados em momentos de crise e conflito, os habitus não precisam ser para se constituírem enquanto habitus, coerentes e homogêneos. Podem ser híbridos, desde que as condições de socialização assim o determinem. As fronteiras entre as matrizes de valores não são sempre explícitas e nunca são vividas como díspares pelos sujeitos pesquisados. Os exercícios de se objetivar e explicar as ações são exercícios interpretativos que buscam sempre a coerência. Para nós, pesquisadores, as incongruências podem ser identificadas, mas nunca serão vividas pelos agentes como tal.

Nesse sentido, crê-se também que o conceito de habitus híbrido é melhor que incoerente ou plural, pois admite mais explicitamente a ideia de criação, amálgama, mistura realizada pela vivência e pela capacidade de cada um montar uma experiência identitária. O conceito de habitus híbrido é melhor também, pois ajuda a pensar a conjunção de elementos de matrizes de cultura díspares, o moderno da escola e da cultura letrada com o tradicional da cultura popular e da oralidade, por exemplo. Não se é sujeito incoerente, é-se o 
resultado de uma história, de um conjunto heterogêneo de experiências de formação cultural que particulariza cada um. Assim, é possível pensar o habitus dos muitos segmentos sociais brasileiros vivendo em formações de cultura diferenciadas, modernas ou tradicionais; é mais fácil compreender as confluências entre as matrizes de cultura em segmentos sociais diferentes que vivem em formações culturais que aparentemente se opõem.

Por exemplo, Norte e Sudeste do Brasil: duas regiões, duas formações de cultura só aparentemente contraditórias, pois elas, enquanto conjunto de experiências, são responsáveis por proporcionar a cultura híbrida do brasileiro; elas estão presentes em todos os lugares e em todos os momentos da experiência de socialização; a circularidade de ideias, objetos, valores, homens moldados por tradições ou moldados por exigências de racionalidade e cálculo se adensa e se mistura em um processo complexo, dinâmico, certamente em ritmos diferenciados mas disponíveis para todos.

Essa é a diferença, não é simplesmente plural nem simplesmente incoerente e contraditório o habitus dos indivíduos da contemporaneidade brasileira. A experiência de socialização vivida em formações sociais como a brasileira impõe pensar os habitus como mais que plurais; eles são produto de experiências de socialização particulares, podem ser resultado de valores identitários oriundos de muitas matrizes de cultura, mas nem por isso são incongruentes ou contraditórios; são híbridos.

Ou talvez habitus sincréticos, pois sua criação admite a perda de alguns aspectos mas a admissão de outros, em um processo de difícil previsão. É produto criativo de sujeitos em situações peculiares e singulares, pois depende de um conjunto de circunstâncias sociais, políticas, religiosas, econômicas, escolares, midiáticas, globalizadas que não se apresentam iguais para todos (Sanchis, 2001). A noção de habitus sincrético admite também a importância do sujeito na construção de sua relação com o mundo exterior, num diálogo constante entre suas necessidades individuais e as referências de cultura disponibilizadas, a busca do indivíduo na construção de sua identidade com base em elementos vindos da objetividade das matrizes de cultura, interpretadas segundo olhares particularizados, não mais agente do processo de socialização passivo, mas sujeito de sua história e ação. Trata-se de um sujeito que nunca se socializa por inteiro mas que se apresenta como sendo resultado de um conjunto de experiências socializadoras, nunca totalizantes mas produto de um processo complexo, dinâmico, produto de uma orquestração de trocas e símbolos identitários, sem maestro, classificados e organizados segundo contextos particulares, ou seja, um produto híbrido, uma espécie, um tipo social resultante de um fenômeno social total, tal como descrito por Marcel Mauss.

\section{Considerações finais}

Como apreender a especificidade do modelo de socialização na atualidade brasileira? Como compreender a particularidade do processo de construção dos habitus com base nas mudanças estruturais e institucionais das agências de socialização?

Como já se fez em outros textos (Setton, 2002a, 2002b), propõe-se responder a essas questões recorrendo à análise da emergência de uma nova configuração cultural, em que o processo de construção dos habitus individuais passa a ser mediado pela coexistência de distintas matrizes produtoras de valores culturais e referências identitárias.

Propõe-se considerar a família, a escola, as instituições religiosas e as mídias, entre outras, no mundo contemporâneo, como instâncias socializadoras que coexistem numa intensa relação de interdependência. Ou seja, instâncias que configuram hoje uma forma permanente e dinâmica de relação. Parte-se da hipótese de que o processo de socialização das formações modernas pode ser considerado um espaço plural de múltiplas relações sociais. Pode ser considerado um campo estruturado pelas relações dinâmicas entre instituições e agentes sociais distintamente posicionados em função de sua visibilidade e recursos disponíveis. Segundo esse modo de ver, salientar a relação de interdependência entre as instâncias e agentes da 
socialização é uma forma de afirmar que as relações estabelecidas entre eles podem ser relações de continuidade ou de ruptura. Podem, pois, determinar uma gama variada e heterogênea de experiências singulares de socialização.

Desta forma, reitera-se, pensar as relações entre a família, a escola, as mídias com base no conceito maussiano de fato social total é analisar essas instituições sociais segundo uma relação dinâmica criada pelo conjunto de seus integrantes, recursos e trajetórias particulares, sobretudo porque a articulação das propostas de socialização de cada uma dessas instituições é atribuição dos sujeitos, variando segundo a origem social, étnica, religiosa, segundo as expectativas de reprodução dos grupos, segundo as experiências individuais deles.

Nesse sentido, a socialização/educação almejada por essas instâncias é fruto de um trabalho individual e coletivo, da troca dialógica entre indivíduo e sociedade. Assim, propõe-se compreender o fenômeno da socialização contemporânea como um fato social total, isto é, uma prática social vivida por uma dinâmica processual, fundada na troca de bens e mensagens simbólicos entre instâncias socializadoras e agentes sociais, prática que envolve simultaneamente a todos, em todas as dimensões da vida dos agentes e tem como tarefa manter o contrato e o funcionamento de um consenso social na unidade da ação individual.

\section{Referências Bibliográficas}

ALMEIDA, Ana; NOGUEIRA, Maria Alice (Orgs.). A escolarização das elites: um panorama internacional de pesquisa. Petrópolis: Vozes, 2003.

BOURDIEU, Pierre Travail et travailleurs en Algérie. Paris: Mouton, 1963.

. Les étudiants et leurs études. Paris: Mouton, 1964a. . Les heritiers, les étudiants et la culture. Paris: Minuit, 1964b.

Un art moyen, essai sur les usages sociaux de la photographie. Paris: Minuit, 1965.

. L'amour de l'art, les musées d'art européens et leur public. Paris: Minuit, 1969.
Esquisse d'une théorie de la pratique - précedé de trois études d'ethnologie kabyle. Paris: Seuil, 2000.

. La distinction - critique social du jugement. Paris: Minuit, 1979.

Le sens pratique. Paris: Minuit, 1980.

A economia das trocas simbólicas. São Paulo:

Perspectiva, 1982.

Questões de sociologia. Rio de Janeiro: Ed. Marco Zero, 1983a.

Pierre Bourdieu. Org. R. Ortiz. São Paulo: Ática, 1983a. Col. Grandes Cientistas Sociais.

Coisas ditas. São Paulo: Brasiliense, 1990.

Pierre Bourdieu avec Löic Wacquant - Réponses.

Paris: Seuil, 1992.

Escritos de educação. Org. Nogueira \& Catani. Petrópolis: Vozes, 1998.

A miséria do mundo. Petrópolis: Vozes,1999.

A produção da crença; contribuição para uma economia dos bens simbólicos. Org. Maria da Graça Setton. São Paulo: Zouk, 2002.

; DARBEL, Alain. O amor pela arte - os museus de arte na Europa e seu público. São Paulo: Zouk, 2003.

LAHIRE, Bernard. Retratos sociológicos; disposições e variações individuais. Porto Alegre: Artes Médicas, 2004a.

O homem plural; os determinantes da ação. Petrópolis: Vozes, 2002

A cultura dos indivíduos. Porto Alegre: Artes Médicas, 2006.

. Trajetória acadêmica e pensamento sociológico. Educação e Pesquisa, São Paulo: FEUSP, p. 315-321, 2004 b.

Sucesso escolar nos meios populares - as razões do improvável. São Paulo: Ática, 1997.

LEVI-STRAUSS, Claude. Introdução à obra de Marcel Mauss. In: MAUSS, Marcel. Sociologia e antropologia. v. 2. São Paulo: EPU/EDUSP, 1974. p. 1-37.

MAUSS, Marcel. Ensaio sobre a dádiva, forma e razão da troca nas sociedades arcaicas. In: Sociologia e antropologia. v. 2. São Paulo: EPU/EDUSP, 1974.

SANCHIS, Pierre. Religiões, religião... Alguns problemas do sincretismo no campo religioso brasileiro. In: (Org.). Fiéis e cidadãos - percursos de sincretismo no Brasil. Rio de Janeiro: Ed. UERJ, 2001. p. 9-57.

SETTON, Maria da Graça J. A teoria do habitus em Pierre Bour- 
dieu: uma leitura contemporânea. Revista Brasileira de Educação, Rio de Janeiro: ANPEd, n. 20, p. 60-70, maio/ago. 2002a.

Família, escola e mídia: um campo com novas configurações. Educação e Pesquisa, São Paulo: FEUSP, v. 28, p. 107-116, jan./jun. 2002b.

A particularidade do processo de socialização contemporâneo. Tempo Social, São Paulo: FFLCH-USP, v. 17, n. 2, p. 335-350, nov. 2005.

VINCENT, Guy. Recherches sur la socialisation démocratique. Lyon: Press Universitaire de Lyon, 2004.

MARIA DA GRAÇA JACINTHO SETTON, doutora em sociologia pela Faculdade de Filosofia, Letras e Ciências Humanas (FFLCH) da Universidade de São Paulo (USP), é professora de sociologia da Faculdade de Educação da mesma instituição. Publicações recentes: Rotary Club: habitus, sociabilidade e estilo de vida (São Paulo: Annablume, 2004); “A teoria do habitus em Pierre Bourdieu: uma leitura contemporânea" (Revista Brasileira de Educação, Rio de Janeiro: ANPEd, n. 20, p. 60-70, maio/ago. 2002); "Família, escola e mídia: um campo com novas configurações” (Educação e Pesquisa, São Paulo: FEUSP, v. 28, p. 107-116, jan./jun. 2002); “A particularidade do processo de socialização contemporâneo” (Tempo Social, São Paulo: FFLCH-USP, v. 17, p. 335-350, nov. 2005). Pesquisa em andamento: "Família, religião, escola e mídia: um estudo sobre as práticas de socialização contemporâneas”.E-mail: gracaset@usp.br

Recebido em junho de 2008 Aprovado em março de 2009 
Palabras-claves: trabajo docente; sindicalismo docente; profesionalidad docente; trabajadores de la educación; CTERA.

Maria da Graça Jacintho Setton

A socialização como fato social total: notas introdutórias sobre a teoria do habitus

O objetivo deste artigo é refletir sobre o processo de socialização segundo a perspectiva da sociologia da educação. Mais precisamente, pensar a teoria da socialização a partir de um ponto de vista relacional, articulando as principais agências educativas da atualidade. Para melhor compreender o fenômeno da socialização contemporânea, propõe-se pensar essa prática como um fato social total, isto é, uma prática social vivida por uma dinâmica processual a partir da troca de bens e mensagens simbólicos entre agências e agentes socializadores, que envolve simultaneamente todos os indivíduos com a tarefa de manter o contrato e o funcionamento da realidade social. Para desenvolver esse argumento, darse-á ênfase a duas teorias da ação que discutem o processo de socialização: a primeira se refere à teoria do habitus, de Pierre Bourdieu; a segunda, àquela desenvolvida por Bernard Lahire que, em uma interpretação particular e crítica a Bourdieu, propõe uma leitura contemporânea da socialização, cunhando a expressão homem plural.

Palavras-chave: fato social total; habitus; homem pural.

\section{Socialization as a total social fact:} introductory notes on the theory of habitus

The objective of this article is to reflect upon the process of socialization from the perspective of the sociology of education. More precisely, to discuss the theory of socialization starting from the relational point of view and articulating the chief current educational agencies. In order to understand better the phenomenon of contemporary socialization, we propose to consider this practice as a total social fact, that is, a social practice lived by a procedural dynamic based on an exchange of goods and symbolic messages between socializing agencies and agents which simultaneously involve all individuals in the task of maintaining the contract and the functioning of social reality. In order to develop this argument, we emphasize two theories of action which discuss the process of socialization: the first refers to Pierre Bourdieu's theory of habitus and the second to that developed by Bernard Lahire who, in a critical interpretation of Bourdieu, proposes a contemporary reading of socialization, coining the expression plural man.

Key words: total social fact; habitus; plural man.

\section{A socialización como hecho social} total: notas introductorias sobre la teoría del habitus

El objetivo de este artículo es reflexionar sobre el proceso de socialización según la perspectiva de la sociología de la educación. Pero precisamente, pensar la teoría de la socialización a partir de un punto de vista relacional, articulando las principales agencias de educación de la actualidad. Para mejor comprender el fenómeno de la socialización contemporánea, se propone pensar esa práctica como un hecho social total, esto es, una práctica social vivida por una dinámica procesal a partir del cambio de bienes y mensajes simbólicos entre agencias y agentes socializadores, que abarca simultáneamente todos los individuos con la tarea de mantener el contrato y el funcionamiento de la realidad social. Para el desarrollo de este argumento, se le dará énfasis a dos teorías de la acción que discuten el proceso de socialización: la primera se refiere a la teoría do habitus, de Pierre Bourdieu; la segunda, aquella dessarrollada por Bernard Lahire que, en una interpretación particular y crítica a Bourdieu, propone una lectura contemporánea de la socialización, acuñando la expresión hombre plural.

Palabras claves: hecho social total; habitus; hombre plural.

Alceu Ravanello Ferraro

Liberalismos e educação. Ou por que o Brasil não podia ir além de Mandeville

Este trabalho examina três autores que expressam versões típicas do liberalismo europeu do século XVIII: o liberalismo de Mandeville, que teme a instrução do povo; o liberalismo de Smith, o qual requer uma instrução mínima (ler, escrever e contar) para todos os trabalhadores; e o liberalismo de Condorcet, que defende uma educação comum, universal, pública, gratuita e obrigatória. Fundamentado no princípio da igualdade de todos os seres humanos, Condorcet contrapõese a Mandeville e avança para além de Smith, que fundamentam suas posições apenas no princípio da liberdade. A opção apoiou-se no pressuposto de que o confronto estabelecido entre eles poderia constituir-se em referência para o entendimento do tipo de liberalismo que vingou no Brasil Império, em especial no momento da reforma eleitoral de 1881, a qual, ao introduzir a eleição direta, determinou a exclusão dos analfabetos do direito de voto, mas é referência também para o entendimento do que se passa hoje no País.

Palavras-chave: liberalismo; Brasil; alfabetização; escolarização.

Liberalisms and education, or why Brazil could not go beyond Mandeville

This paper discusses three authors who express three typical versions 